UDC 343.1:33

LBC 67.410 .2

\title{
MODERN CRIMINAL POLICY OF ENSURING ECONOMIC SECURITY BY CRIMINAL PROCEDURE MEANS
}

\author{
Olga V. Gladysheva \\ Kuban State University, Krasnodar, Russian Federation \\ Vladimir A. Sementsov \\ Kuban State University, Krasnodar, Russian Federation
}

\begin{abstract}
Introduction: criminal justice is becoming increasingly important as a means of ensuring the national security in general and in criminal cases involving economic crimes in particular. The optimization of the criminal procedure form in criminal cases of economic orientation is a consequence of the targeted state criminal law policy. In this connection, the goal of this study is to give a scientific assessment of the measures taken by the legislator to improve the criminal procedure law and further prospects for the development and improvement of the procedure in this category of criminal cases. Methods: the methodological framework for the research is the traditional methods of scientific cognition, the main of which are the methods of analysis, synthesis, generalization, abstraction, modeling, etc. Results: the concept of the continuation of the reformation of criminal proceedings in order to optimize the procedure of criminal proceedings of economic orientation is based on the legislation and the competent opinions of the academic community. Conclusions: the conducted research has allowed formulating the author's original concept of improvement of the criminal procedural legislation regarding the creation of optimum procedure of investigation and judicial consideration of criminal cases of economic orientation concerning the businessmen. The article substantiates the necessity of the fundamental revision of the criminal law policy in terms of providing the accused entrepreneurs with additional preferences.
\end{abstract}

Key words: national security, criminal proceedings, economic security, entrepreneur, policy, preventive measures, termination of a criminal case.

УДК $343.1: 33$

ББК 67.410 .2

\section{СОВРЕМЕННАЯ УГОЛОВНО-ПРАВОВАЯ ПОЛИТИКА ПО ОБЕСПЕЧЕНИЮ ЭКОНОМИЧЕСКОЙ БЕЗОПАСНОСТИ УГОЛОВНО-ПРОЦЕССУАЛЬНЫМИ СРЕДСТВАМИ}

\author{
Ольга Владимировна Гладышева \\ Кубанский государственный университет, г. Краснодар, Российская Федерация \\ Владимир Александрович Семенцов \\ Кубанский государственный университет, г. Краснодар, Российская Федерация
}

Введение: уголовное судопроизводство приобретает все большее значение в качестве средства обеспечения национальной безопасности в целом, и по уголовным делам об экономических преступлениях в частности. Оптимизация уголовно-процессуальной формы по уголовным делам экономической направленности выступает следствием целенаправленной государственной уголовно-правовой политики. В связи с этим определена цель данного исследования - дать научную оценку предпринятых законодателем мер по совершенствованию уголовно-процессуального права и дальнейших перспектив развития и совершенствования процедуры по указанной категории уголовных дел. Методы: методологическую основу исследования составили традиционные методы научного познания, основными из которых стали методы анализа, синтеза, 
обобщения, абстрагирования, моделирования и др. Результаты: высказанная в работе концепция о продолжении реформирования уголовного судопроизводства в целях оптимизации процедуры производства по уголовным делам экономической направленности опирается на законодательство и имеющиеся компетентные мнения научного сообщества. Выводы: проведенное исследование позволило сформулировать авторскую оригинальную концепцию совершенствования уголовно-процессуального законодательства в части создания оптимальной процедуры расследования и судебного рассмотрения уголовных дел экономической направленности в отношении предпринимателей. Обосновывается необходимость кардинального пересмотра уголовно-правовой политики в части наделения обвиняемых-предпринимателей дополнительными преференциями.

Ключевые слова: национальная безопасность, уголовное судопроизводство, экономическая безопасность, предприниматель, политика, меры пресечения, прекращение уголовного дела.

\section{Введение}

Национальная безопасность современного государства является сложной категорией, включающей множество составляющих элементов. Современное определение понятия «национальная безопасность» основывается на различных научных мнениях и позициях. Имеется также и легальное его определение $[1 ; 2 ; 5 ; 7 ; 16]$. Структура национальной безопасности включает множество элементов, выделяются уровни национальной безопасности. Элементами национальной безопасности рассматриваются государственная, общественная, техногенная, экологическая, экономическая, энергетическая и информационная сферы. В литературе выделяются отдельные виды национальной безопасности: политической, экономической, информационной, экологической, военной, социальной и др. [14].

При существенной разнице в количестве и содержании элементов все авторы сходятся во мнении, что обязательным элементом национальной безопасности является экономическая безопасность, которую определяют как состояние экономики, при котором обеспечивается процесс устойчивого развития, а также социальноэкономическая стабильность общества независимо от наличия и действия внешних факторов. Проблемы национальной экономической безопасности все чаще становятся предметом изучения представителей различных наук.

Как представляется, правильную позицию занимает Н.В. Дементьев, отмечающий следующее: «...экономическая безопасность в данном контексте играет весомую роль, так как все вышеперечисленные виды безопасности в той или иной степени не могут быть реализованы без экономического обеспечения» [4, с. 78].

\section{Национальная безопасность и ее структурный элемент - экономическая безопасность}

Есть мнение, что «экономическая безопасность традиционно рассматривается как важнейшая качественная характеристика экономической системы государства, которая определяет ее способность поддерживать нормальные условия жизнедеятельности населения, устойчивое обеспечение ресурсами развития народного хозяйства, а также последовательную реализацию национально- государственных интересов» [22, c. 239-240]. Учитывая значимость экономического базиса, мы полагаем, что логика рассуждений в данном случае должна быть иной: не безопасность выступает характеристикой экономики, а именно экономика определяет уровень экономической безопасности государства.

Определение уровня экономической безопасности проводится на основании множества (до 150) критериев, включая объем ВВП, валовый сбор зерновых, долю инвестиций в основной капитал, расходы на оборону, долю затрат на «гражданскую» науку, долю инновационной продукции в общем объеме промышленной продукции, долю машиностроения и металлообработки в промышленном производстве [22].

Полагаем, что оценка уровня экономической безопасности исключительно на основании структурных и цифровых показателей является односторонней, она не способна отразить все факторы, оказывающие воздействие как на отельные секторы экономики, так и на экономический потенциал государства в целом. 
Дополнительным (но отнюдь не второстепенным), на наш взгляд, выступает такой показатель, как уровень правового обеспечения хозяйственной деятельности, степень развитости правовых отношений внутри экономического сектора, рациональность и эффективность выстраивания отношений в системе государство - хозяйствующие субъекты.

Правовая основа является обязательным атрибутом и сопутствует всем этапам и направлениям экономической деятельности от организации предприятия до выполнения отдельных работ или оказания услуг. Государство не может отказаться от правового регулирования отношений с хозяйствующими субъектами в силу значимости экономического потенциала, влияния экономических показателей на все сферы государственного устройства.

Выстраивание отношений между органами государственной власти и хозяйствующими субъектами происходит не только в порядке организационного взаимодействия, включая контроль за деятельностью этих субъектов, но и путем ограничений направлений экономической деятельности либо определением условий ее осуществления, в том числе путем установления правовых запретов.

Государство в отношениях с субъектами экономической деятельности определяет приоритеты, которые, в свою очередь, обусловливают содержание и направленность государственной политики, включая правовую сферу. Формирование современной российской правовой политики в сфере экономики происходит под воздействием декларируемой государством идеи поддержания наиболее благоприятного климата для развития предпринимательства, его устойчивости и социальной приоритетности. И в данном направлении предпринимаются многочисленные и весьма разнообразные шаги, комплексно воздействующие на все стороны правовой жизни, необходимые для развития предпринимательства: принимаются законодательные и иные нормативно-правовые акты, создаются государственные (федеральные и региональные) программы по поддержке малого и среднего предпринимательства, снижаются налоговая и иные виды финансовой нагрузки на начинающих предпринимателей $[3 ; 11]$.
На предпринимательство государство возлагает большие надежды в связи с необходимостью обеспечивать население занятостью, а также услугами в сфере общественного питания, ЖКХ, образования, бытового обслуживания, мелких партий товаров бытового назначения и др. Это достаточно большой сектор экономики, имеющий высокую степень социальной значимости.

Для расширения сферы предпринимательства большую роль играет правовая защищенность хозяйствующих субъектов, от чего в значительной степени зависит «инвестиционная привлекательность страны» [15, c. 32]. Поэтому отдельная часть комплекса мер по поддержке предпринимательства направлена на совершенствование правовой основы, в том числе уголовно-процессуального права, для устранения потенциальных угроз финансовой и экономической деятельности и стабильности функционирования хозяйствующих субъектов, ограждения их от применения необоснованных мер уголовно-процессуального принуждения, исключения злоупотреблений со стороны органов уголовного преследования и иных неблагоприятных факторов.

\section{Уголовное судопроизводство и его воздействие на уровень экономической безопасности}

В одном из своих выступлений Президент РФ В.В. Путин предложил запретить следственным органам изымать серверы и жесткие диски при проведении следственных мероприятий на предприятиях [12]. 17 августа 2017 г. Президент РФ дал поручения Правительству РФ совместно с Верховным судом РФ и Генеральной прокуратурой РФ проработать вопрос о недопущении продления меры пресечения в виде содержания под стражей (ареста) в отношении лиц, подозреваемых и обвиняемых в совершении преступлений в сфере предпринимательской деятельности, в случае, если по уголовному делу не предпринимаются активные следственные действия, а при необходимости предусмотреть внесение в законодательство РФ соответствующих изменений [9].

Политическая воля руководства страны привела к существенной корректировке содержания уголовно-процессуального законода- 
тельства в части составов преступлений, отнесенных к категории частно-публичного обвинения [18], касающихся экономической деятельности, дополнены основания [17] и скорректирован порядок возбуждения уголовных дел и отказа в возбуждении [19], а также порядок прекращения уголовных дел [20], дополнена совокупность прав подозреваемых в совершении экономического преступления, находящихся под стражей [18].

По справедливому замечанию многих авторов, появление в уголовном судопроизводстве новелл в отношении предпринимателей обусловлено в большей степени политическими, нежели юридическими причинами. Цель законодателя - продемонстрировать уменьшение государственного давления на бизнес [8, с. 65].

Современная ситуация приводит к двум промежуточным выводам:

1) уголовное судопроизводство рассматривается в качестве правового средства обеспечения национальной безопасности в целом, и ее экономического направления в частности;

2) использование ресурса уголовного судопроизводства для обеспечения экономической безопасности происходит путем создания преференций для лиц, являющихся предпринимателями и обвиняемых в совершении экономических преступлений, совершенных в сфере предпринимательской деятельности.

Указанные обстоятельства, как представляется, составляют основу уголовно-правовой политики и свидетельствуют о приобретении уголовным судопроизводством самостоятельного значения в качестве средства правового обеспечения национальной безопасности, ее экономической составляющей.

В целом такого рода политика представляется целесообразной, оправданной и своевременной. В частности, можно полностью согласиться с отдельными особенностями, установленными в отношении порядка изъятия вещественных доказательств, электронных носителей, который продиктован стремлением обезопасить деятельность хозяйствующего субъекта, воспрепятствовать необоснованному прекращению этой деятельности или созданию для нее препятствий.

Однако, оценивая последствия иных предпринимаемых законодателем шагов, нужно отметить отдельные проблемы:
1. Экономические преступления причиняют вред именно экономике страны. Следовательно, предотвращение и эффективное противодействие таким преступлениям играет важную роль в обеспечении экономической безопасности государства. Снижение же, например, уровня уголовно-процессуального принуждения может расцениваться как слабость государства, отсутствие воли к противодействию такого рода преступлениям.

Положения УПК РФ в части применения меры пресечения в виде заключения под стражу неоднократно дополнялись, и в настоящее время предусматривают категорический запрет на применение заключения под стражу в отношении подозреваемого или обвиняемого в совершении преступлений, предусмотренных ст. 159-159.3, 159.5, 159.6, 160, 165 , если эти преступления совершены в сфере предпринимательской деятельности, а также ст. 171-174, $174.1,176-178,180-183,185-$ 185.4, 190-199.4 УК РФ при отсутствии обстоятельств, указанных в п. 1-4 ч. 1 ст. 108 УПК РФ. В остальной части особенностей избрания мер пресечения в отношении этой группы субъектов в законе не предусматривается.

Однако и то, что уже предусмотрено законодателем, позволяет сделать вывод о наличии следующих проблемных аспектов:

1) неполнота определения составов преступления, которые относятся к хозяйственной деятельности; полагаем, что ст. 200.3 УК РФ (привлечение денежных средств граждан в нарушение требований законодательства Российской Федерации об участии в долевом строительстве многоквартирных домов и (или) иных объектов недвижимости) имеет те же основные характеристики, что и перечисленные в ч. 1.1 ст. 108 УК РФ;

2) избрание заключения под стражу по ст. 159-159.3, 159.5, 159.6, 160, 165 УК РФ поставлено в зависимость от установления факта совершения преступлений в сфере предпринимательской деятельности. Подчеркнем еще раз, что сфера предпринимательской деятельности не имеет четко выраженных законодательных границ, и по сути - нет легального ее определения. В ч. 1 ст. 2 ГК РФ предусмотрено, что «предпринимательской является самостоятельная, осуществ- 
ляемая на свой риск деятельность, направленная на систематическое получение прибыли от пользования имуществом, продажи товаров, выполнения работ или оказания услуг». Федеральный закон от 24 июля 2007 г. № 209-Ф3 «О развитии малого и среднего предпринимательства в Российской Федерации» даже в основных понятиях не раскрывает суть категории «предпринимательская деятельность» (ст. 3) [21]. Получается, что для практической реализации положений ч. 1.1 ст. 108 УПК РФ органы предварительного расследования должны установить, занимается ли субъект самостоятельной, направленной на систематическое получение прибыли от пользования имуществом, продажи товаров или выполнения работ, оказания услуг деятельностью. Тогда возникает другой вопрос: почему в ст. 20 УПК РФ говорится только о лицах, занимающих руководящее положение в структуре предприятия, общества? Причем только о тех, которые наделены властно-распорядительными и, в основном, - организационными и контрольными полномочиями? В этом вопросе, полагаем, ясности нет;

3) на фоне недостаточно четкого процессуального законодательства неизбежны проблемы правоприменения. Изученные судебные материалы свидетельствуют об очень большом различии в подходах судей при избрании заключения под стражу в качестве меры пресечения в отношении хозяйствующих субъектов.

Так, следователь отдела СЧ ГСУ ГУ МВД России по Пермскому краю обратился в суд с ходатайством об изменении X. меры пресечения в виде залога на заключение под стражу. Постановлением судьи Свердловского районного суда г. Перми в удовлетворении ходатайства следователя отказано, хотя основанием для ходатайства следователя стали следующие обстоятельства:

- получение X. временного паспорта гражданина Республики Болгария, при этом из приложения к Постановлению Правительства РФ от 21 февраля 2002 г. № 122 «О подписании Соглашения между Правительством Российской Федерации и Правительством Республики Болгарии о взаимных поездках граждан» следует, что временный паспорт пред- полагает однократное пересечение границы Российской Федерации только при выезде за ее пределы;

- задержание X. 27 июня 2017 г. при попытке по вышеуказанному паспорту пересечь границу Российской Федерации в направлении Республики Казахстан через пограничный пост в П. Петухово;

- отсутствие разрешения от следователя о передвижении по территории Российской Федерации, а также о выезде за ее пределы;

- неуведомление X. об изменении своего местонахождения органов следствия.

Апелляционная инстанция указала, что сам по себе факт задержания X. на пограничном пункте и наличие у него временного паспорта гражданина Республики Болгария не свидетельствуют о намерении Х. выехать за пределы Российской Федерации именно с иелью скрыться от органов следствия. В удовлетворении апелляционного представления прокурора отказано [10].

В.В. Рудич отмечает: «Судебная практика выявила несколько ситуаций, при которых суды находили возможным применение данной меры пресечения к лицам, занимающимся предпринимательской деятельностью: во-первых, это когда обвиняемому инкриминировалось какое-либо из преступлений, не указанных в ч. 1.1 ст. 108 УПК РФ, во-вторых, когда находились данные, указывающие на наличие обстоятельств, перечисленных в пп. 1-4 ч. 1 ст. 108 УПК РФ (в частности, что он скрывался или пытался скрыться от органов следствия), в-третьих, когда подтверждалось, что предпринимательство являлось формой прикрытия преступной деятельности» [13, с. 199].

Думается, что значение уголовного судопроизводства состоит в том, чтобы определить оптимальный порядок выяснения всех существенных обстоятельств, обеспечивать своевременное, законное и обоснованное привлечение к уголовной ответственности за совершение преступления. Это общая (универсальная) задача уголовного судопроизводства, которая решается не только применительно к экономическим, но и ко всем остальным категориям преступлений. Поэтому считаем установление специальных правил применения мер уголовно-процессуального принуждения в 
отношении предпринимателей неоправданным шагом законодателя.

Более правильным представляется мнение В.А. Ионова, который предлагает создать такие условия, которые приведут к «невыгодности» совершения преступлений корыстной направленности [6, с. 12]. Эту позицию следует учитывать при дальнейшем формировании уголовно-правовой политики в сфере уголовного судопроизводства. Так, наличие порядка, при котором незаконное завладение имуществом не будет приносить пользы приобретателям, так как им нельзя будет пользоваться, подорвет основу экономической преступности в ее наиболее опасных проявлениях.

2. Уголовно-правовые и гражданско-правовые отношения в сфере экономической деятельности нередко тесно соприкасаются, и их разграничение представляет серьезную проблему для правоприменителя. В данном направлении законодателем не предпринято никаких эффективных шагов.

3. Происходящие изменения в уголовном судопроизводстве затрагивают исключительно предпринимателей-обвиняемых, оставляя в стороне интересы потерпевших. Дело в том, что в УПК РФ отсутствуют какие-либо упоминания о собственниках предприятий и иных хозяйствующих субъектов. О специфике процессуальной фигуры потерпевшего законодатель не упоминает ни в ст. 20 УПК РФ (поставив в зависимость от потерпевшего возбуждение уголовного дела, при этом потерпевшим выступает орган управления хозяйствующим субъектом), ни в иных положениях. Получается, что лица, управляющие имуществом, имеют преимущества в процессуальном положении в сравнении с собственником.

Считаем, что отсутствие специальных правил для определения и признания лица потерпевшим по делам соответствующей категории является пробелом действующего уголовно-процессуального закона. На наш взгляд, это обстоятельство должно быть учтено при формировании общего положения о потерпевшем в ч. 1 ст. 42 УПК РФ. Причем необходимо скорректировать порядок возбуждения и отказа в возбуждении уголовных дел данной категории, поставив принятие этих решений в указанных законом условиях в зависимость от воли потерпевшего-собственника.

\section{Выводы}

Подводя итог, отметим главное:

1. Уголовно-правовая политика в сфере обеспечения экономической безопасности определяет современные тенденции развития многих правовых сфер, включая уголовно-процессуальную.

2. В соответствии с уголовно-правовой политикой, уголовное судопроизводство по уголовным делам, связанным с участием хозяйствующих субъектов, осуществляется по специальным правилам, в числе которых можно назвать особенности возбуждения уголовных дел по заявлению коммерческой организации, прекращение уголовных дел указанной категории, изъятие вещественных доказательств, применение мер пресечения в отношении предпринимателей и многие другие.

3. Отдельные меры, реализуемые законодателем в соответствии с избранной политикой в отношении хозяйствующих субъектов, можно считать оправданными, другие же приводят к возникновению существенных проблем и противоречий в ходе производства по уголовным делам.

4. Насущной становится потребность в приведении уголовно-процессуального законодательства к единообразию в вопросах определения:

- предмета доказывания;

- процессуального режима по избранию меры пресечения в отношении лиц, обвиняемых в совершении экономических преступлений, при различии в уголовно-правовой квалификации;

- процессуального статуса потерпевшихсобственников.

5. Приходится констатировать отсутствие шагов законодателя по устранению фундаментальных ошибок органов предварительного расследования по экономическим преступлениям, связанных с разграничением гражданско-правовых и уголовноправовых отношений. В данном направлении представляется актуальным усиление прокурорского надзора за качеством (законностью и обоснованностью) принимаемых органами предварительного расследования решений. 


\section{СПИСОК ЛИТЕРАТУРЫ}

1. Борисенко, Е. Н. Продовольственная безопасность России: проблемы и перспективы / Е. Н. Борисенко.-М. : Экономика, 1997. - С. 330-337.

2. Бушуев, В. А. Понятие национальной безопасности в отечественном и зарубежном государственно-правовом дискурсе / В. А. Бушуев // Известия ЮФУ. Технические науки. - 2013. № 6 (143). - С. 179-186.

3. Государственная программа «Развитие малого и среднего предпринимательства Российской Федерации. Экономическое развитие и инновационная экономика». Государственные ассигнования составят в 2018 году 5767864,4 тыс. рублей // Судебные и нормативные акты РФ. - Электрон. текстовые дан. - Режим доступа: http://sudact.ru/law/postanovlenie-pravitelstvarf-ot-15042014-n-316/gosudarstvennaia-programmarossiiskoi-federatsii-ekonomicheskoe/pasportpodprogrammy-2-razvitie-malogo. - Загл. с экрана.

4. Дементьев, Н. В. Экономическая безопасность в структуре национальной безопасности современной России / Н. В. Дементьев // Социально-экономические явления и процессы. - 2011. № 5-6. - С. 76-82.

5. Закон Российской Федерации «О безопасности» от 05 марта 1992 г. № 2446-1 : (ред. от 02 марта 2007 г.) // Российская газета. - 1992. - 6 мая (№ 103).

6. Ионов, В. А. Наложение ареста на имущество при производстве предварительного расследования по уголовным делам об экономических преступлениях : дис. ... канд. юрид. наук / Ионов Владимир Алексеевич. - Н. Новгород, 2010 - 246 с.

7. Колобов, О. А. Национальные интересы современной России и экономическая безопасность государства / О. А. Колобов // Экономическая безопасность России: политические ориентиры, законодательные приоритеты, практика обеспечения: Вестник Нижегородской академии МВД России. - 2001. - № 1.

8. Комментарий к Уголовно-процессуальному кодексу РФ / науч. ред. В. Т. Томин, М. П. Поляков. 5-е изд., перераб. и доп. - М. : Юрайт, 2011. - 1087 с.

9. Перечень поручений Президента Российской Федерации от 15 августа 2017 г. - Электрон. текстовые дан. - Режим доступа: http://kremlin.ru/acts/ assignments/orders/55368. - Загл. с экрана.

10. Пермский краевой суд. Апелляционное постановление по уголовномуделу № 22К-4376. -2017.

11. Постановление Правительства РФ «О предоставлении и распределении субсидий из федерального бюджета бюджетам субъектов Российской Федерации на государственную поддержку малого и среднего предпринимательства, включая крестьянские (фермерские) хозяйства» от 30 дек. 2014 г. № 1605. - Доступ из справ.-правовой системы «КонсультантПлюс».
12. Путин: нужно запретить следствию изымать серверы и жесткие диски предприятий // ТАСС: Информационное агентство России. - Электрон. текстовые дан. - Режим доступа: http://tass.ru/ obschestvo/4459762. - Загл. с экрана.

13. Рудич, В.В.Применение меры пресечения в виде заключения под стражу в отношении подозреваемых и обвиняемых в совершении преступлений в сфере предпринимательской и иной экономической деятельности / В. В. Рудич // Общество и право. -2015. - № 1 (51). - С. 197-202.

14. Семенцов, В. А. Основы теории национальной безопасности : учеб. пособие / В. А. Семенцов. Краснодар : Изд-во Кубан. гос. ун-та, 2015. - 208 с.

15. Сычев, П. Г. Правовая защита субъектов предпринимательской деятельности: проблемы уголовного судопроизводства / П. Г. Сычев // Предпринимательское право. - 2012. - № 4. - С. 30-34.

16. Указ Президента РФ «Об утверждении Концепции национальной безопасности Российской Федерации» от 17 дек. 1997 г. № 1300 : (в ред. Указа Президента РФ от 10 янв. 2000 г. № 24) (в соответствии с Указом Президента РФ от 12 мая 2009 г. № 537 утратила силу) // Российская газета. - 1997. 26 дек. (№ 247).

17. Федеральный закон «О внесении изменений в отдельные законодательные акты Российской Федерации» от 21 июля 2014 г. № 218-Ф3 : (ред. От 30 дек. 2015 г., с изм. и доп., вступ. в силу с 01 июля 2016 г.) // Собрание законодательства РФ. - 2014. № 30 (ч. I). - Ст. 4219.

18. Федеральный закон «О внесении изменений в Уголовный кодекс Российской Федерации и Уголовно-процессуальный кодекс Российской Федерации» от 3 июля 2016 г. № 325-Ф3 // Собрание законодательства РФ. -2016. - № 27 (ч. II). - Ст. 4258.

19. Федеральный закон «О внесении изменений в Уголовный кодекс Российской Федерации и Уголовно-процессуальный кодекс Российской Федерации в связи с совершенствованием правового регулирования отношений, связанных с уплатой страховых взносов в государственные внебюджетные фонды» от 29 июля 2017 г. № 250-Ф3 // Собрание законодательства РФ. - 2017. - № 31 (ч. І). С. 4799.

20. Федеральный закон «О добровольном декларировании физическими лицами активов и счетов (вкладов) в банках и о внесении изменений в отдельные законодательные акты Российской Федерации» от 8 июня 2015 г. № 140-Ф3 : (ред. от 05 апр. 2016) // Собрание законодательства РФ. - 2015. № 24. - Ст. 3367.

21. Федеральный закон «О развитии малого и среднего предпринимательства в Российской Федерации» от 24 июля 2007 г. № 209-Ф3 // Собрание законодательства РФ. - 2007. - № 31. - Ст. 4006. 
22. Экономическая безопасность Российской Федерации: современное состояние, уровень и угрозы / В. В. Григорьева, Г. Н. Струков, Ю. И. Слепокурова, А. А. Слепокурова // Вестник ВГУИТ. 2017. - Т. 79, № 3. - С. 238-252.

\section{REFERENCES}

1. Borisenko E.N. Prodovolstvennaya bezopasnost Rossii: problemy i perspektivy [Food Security of Russia: Problems and Perspectives]. Moscow, Ekonomika Publ., 1997, pp. 330-337.

2. Bushuev V.A. Ponyatie natsionalnoy bezopasnosti $\mathrm{v}$ otechestvennom i zarubezhnom gosudarstvenno-pravovom diskurse [The Notion of National Security in Domestic and Foreign State-Legal Discourse]. Izvestiya YuFU. Tekhnicheskie nauki, 2013, no. 6 (143), pp. 179-186.

3. Gosudarstvennaya programma «Razvitie malogo i srednego predprinimatelstva Rossiyskoy Federatsii. Ekonomicheskoe razvitie i innovatsionnaya ekonomika». Gosudarstvennye assignovaniya sostavyat v 2018 godu 5767864,4 tys. rubley [State Program 'Development of Small and Medium-Sized Business in the Russian Federation. Economic Development and Innovative Economy'. State Appropriations Will Amount to 5,767,864.4 Thousand Rubles in 2018]. Sudebnye i normativnye akty $R F$ [Judicial and Regulatory Acts of the Russian Federation]. URL: http://sudact.ru/law/postanovleniepravitelstva-rf-ot-15042014-n-316/gosudarstvennaiaprogramma-rossiiskoi-federatsii-ekonomicheskoe/ pasport-podprogrammy-2-razvitie-malogo.

4. Dementyev N.V. Ekonomicheskaya bezopasnost $\mathrm{v}$ strukture natsionalnoy bezopasnosti sovremennoy Rossii [Economic Security in the Structure of the National Security of Modern Russia]. Sotsialno-ekonomicheskie yavleniya i protsessy, 2011, no. 5-6, pp. 76-82.

5. Zakon Rossiyskoy Federatsii «O bezopasnosti» ot 05 marta 1992 g. № 2446-1: (red. ot 02 marta 2007 g.) [Law of the Russian Federation 'On Security' of March 5, 1992 No. 2446-1: (ed. of March 2, 2007)]. Rossiyskaya gazeta, 1992, no. 103, May 6.

6. Ionov V.A. Nalozhenie aresta na imushchestvo pri proizvodstve predvaritelnogo rassledovaniya po ugolovnym delam ob ekonomicheskikh prestupleniyakh: dis.... kand. yurid. nauk [Attachment of Property During the Preliminary Investigation of Criminal Cases on Economic Crimes. Cand. jurid. sci. diss.]. Nizhny Novgorod, 2010. 246 p.

7. Kolobov O.A. Natsionalnye interesy sovremennoy Rossii i ekonomicheskaya bezopasnost gosudarstva [National Interests of Modern Russia and the Economic Security of the State].
Ekonomicheskaya bezopasnost Rossii: politicheskie orientiry, zakonodatelnye prioritety, praktika obespecheniya: Vestnik Nizhegorodskoy akademii MVD Rossii, 2001, no. 1.

8. Tomin V.T., Polyakov M.P., eds. Kommentariy k Ugolovno-protsessualnomu kodeksu RF [Commentary to the Criminal Procedure Code of the Russian Federation]. Moscow, Yurayt Publ., 2011. 1087 p.

9. Perechen porucheniy Prezidenta Rossiyskoy Federatsii ot 15 avgusta $2017 \mathrm{~g}$. [The List of Instructions of the President of the Russian Federation of August 15, 2017]. URL: http://kremlin.ru/acts/ assignments/orders/55368.

10. Permskiy kraevoy sud. Apellyatsionnoe postanovlenie po Ugolovnomu delu № $22 \mathrm{~K}-4376$ [Appeal Decision on Criminal case No. 22K-4376]. Perm Regional Court, 2017.

11. Postanovlenie Pravitelstva RF "O predostavlenii $i$ raspredelenii subsidiy $i z$ federalnogo byudzheta byudzhetam subyektov Rossiyskoy Federatsii na gosudarstvennuyu podderzhku malogo i srednego predprinimatelstva, vklyuchaya krestyanskie (fermerskie) khozyaystva» ot 30 dek. 2014 g. № 1605 [Resolution of the Government of the Russian Federation 'On Provision and Distribution of Subsidies from the Federal Budget to the Budgets of the Constituent Entities of the Russian Federation for State Support of Small and Medium-Sized Business, Including Peasant (Farmer) Economies' of December 30, 2014 No. 1605]. Access from Reference Legal System KonsultantPlyus.

12. Putin: nuzhno zapretit sledstviyu izymat servery i zhestkie diski predpriyatiy [Putin: We Need to Prohibit the Investigators to Remove Servers and Hard Drives of Enterprises]. TASS: Informatsionnoe agentstvo Rossii [TASS Information Agency of Russia]. URL: http://tass.ru/obschestvo/4459762.

13. Rudich V.V. Primenenie mery presecheniya $\mathrm{V}$ vide zaklyucheniya pod strazhu $\mathrm{v}$ otnoshenii podozrevaemykh i obvinyaemykh $\mathrm{v}$ sovershenii prestupleniy $\mathrm{v}$ sfere predprinimatelskoy i inoy ekonomicheskoy deyatelnosti [Application of the Preventive Measure in the Form of Detention in Respect of Suspects and Accused of Committing Crimes in the Field of Entrepreneurial and Other Economic Activities]. Obshchestvo i pravo, 2015, no. 1 (51), pp. 197-202.

14. Sementsov V.A. Osnovy teorii natsionalnoy bezopasnosti: ucheb. posobie [The Fundamentals of the Theory of National Security: Textbook]. Krasnodar, Kuban. gos. un-t Publ., 2015. 208 p.

15. Sychev P.G. Pravovaya zashchita subyektov predprinimatelskoy deyatelnosti: problemy ugolovnogo sudoproizvodstva [Legal Protection of Business Entities: the Problems of Criminal Justice]. Predprinimatelskoe pravo, 2012, no. 4, pp. 30-34. 
16. Ukaz Prezidenta RF «Ob utverzhdenii Kontseptsii natsionalnoy bezopasnosti Rossiyskoy Federatsii» ot 17 dek. 1997 g. № 1300: (v red. Ukaza Prezidenta RF ot 10 yanv. 2000 g. № 24) (v sootvetstvii s Ukazom Prezidenta RF ot 12 maya 2009 g. № 537 utratila silu) [Decision of the President of the Russian Federation 'On the Approval of the Concept of National Security of the Russian Federation' of December 17, 1997 No. 1300: (Amended by Presidential Decree No. 24 of January 10, 2000 ) (in accordance with Presidential Decree No. 537 of May 12, 2009, expired)]. Rossiyskaya gazeta, 1997, December 26 (no. 247).

17. Federalnyy zakon «O vnesenii izmeneniy v otdelnye zakonodatelnye akty Rossiyskoy Federatsii» ot 21 iyulya 2014 g. № 218-FZ : (red. ot 30 dek. 2015 g., s izm. i dop., vstup. v silu s 01 iyulya 2016 g.) [The Federal Law 'On Amendments to Certain Legislative Acts of the Russian Federation' of July21, 2014 No. 218FL: (ed. of December 30, 2015, with amendments and supplements, came into force on July 1, 2016)]. Sobranie zakonodatelstva RF [Collected Legislation of the Russian Federation], 2014, no. 30 (part I), art. 4219.

18. Federalnyy zakon «O vnesenii izmeneniy v Ugolovnyy kodeks Rossiyskoy Federatsii i Ugolovnoprotsessualnyy kodeks Rossiyskoy Federatsii» ot 3 iyulya 2016 g. № 325-FZ [Federal Law 'On Amendments to the Criminal Code of the Russian Federation and to the Code of Criminal Procedure of the Russian Federation' of July 3, 2016 No. 325-FL]. Sobranie zakonodatelstva $R F$ [Collected Legislation of the Russian Federation], 2016, no. 27 (part II), art. 4258.

19. Federalnyy zakon «O vnesenii izmeneniy v Ugolovnyy kodeks Rossiyskoy Federatsii i Ugolovnoprotsessualnyy kodeks Rossiyskoy Federatsii v svyazi s sovershenstvovaniem pravovogo regulirovaniya otnosheniy, svyazannykh s uplatoy strakhovykh vznosov v gosudarstvennye vnebyudzhetnye fondy» ot 29 iyulya 2017 g. № 250-FZ [Federal Law 'On Amendments to the Criminal Code of the Russian Federation and to the Code of Criminal Procedure of the Russian Federation in Connection with the Improvement of Legal Regulation of Relations Associated with the Payment of Insurance Payments to State Extra-Budgetary Funds' of July 29, 2017 No. 250-FL]. Sobranie zakonodatelstva $R F$ [Collected Legislation of the Russian Federation], 2017, no. 31 (part I), art. 4799.

20. Federalnyy zakon «O dobrovolnom deklarirovanii fizicheskimi litsami aktivov i schetov (vkladov) v bankakh i o vnesenii izmeneniy v otdelnye zakonodatelnye akty Rossiyskoy Federatsii» ot 8 iyunya 2015 g. № 140-FZ: (red. ot 05 apr. 2016) [The Federal Law 'On Voluntary Declaration of Assets and Accounts (Deposits) in Banks by Individuals and on Amendments to Certain Legislative Acts of the Russian Federation' of June 8, 2015 No. 140-FL: (ed. of April 5, 2016)]. Sobranie zakonodatelstva $R F$ [Collected Legislation of the Russian Federation], 2015, no. 24, art. 3367.

21. Federalnyy zakon «O razvitii malogo i srednego predprinimatelstva v Rossiyskoy Federatsii» ot 24 iyulya 2007 g. № 209-FZ [Federal Law 'On the Development of Small and Medium-Sized Enterprises in the Russian Federation' of July 24, 2007 No. 209-FL]. Sobranie zakonodatelstva RF [Collected Legislation of the Russian Federation], 2007, no. 31, art. 4006.

22. Grigoryeva V.V., Strukov G.N., Slepokurova Yu.I., Slepokurova A.A. Ekonomicheskaya bezopasnost Rossiyskoy Federatsii: sovremennoe sostoyanie, uroven i ugrozy [Economic Security of the Russian Federation: Modern Conditions and Threats]. Vestnik VGUIT, 2017, vol. 79, no. 3, pp. 238-252.

\section{Information about the Authors}

Olga V. Gladysheva, Doctor of Sciences (Jurisprudence), Professor, Head of Department of Criminal Procedure, Kuban State University, Stavropolskaya St., 149, 350040 Krasnodar, Russian Federation, volkolup@yandex.ru.

Vladimir A. Sementsov, Doctor of Sciences (Jurisprudence), Professor, Head of Department of Criminal Procedure, Kuban State University, Stavropolskaya St., 149, 350040 Krasnodar, Russian Federation, crimpro@yandex.ru.

\section{Информация об авторах}

Ольга Владимировна Гладышева, доктор юридических наук, профессор, заведующая кафедрой уголовного процесса, Кубанский государственный университет, ул. Ставропольская, 149, 350040 г. Краснодар, Российская Федерация, volkolup@yandex.ru.

Владимир Александрович Семенцов, доктор юридических наук, профессор кафедры уголовного процесса, Кубанский государственный университет, ул. Ставропольская, 149, 350040 г. Краснодар, Российская Федерация, crimpro@yandex.ru. 